\section{Opinions . .}

\section{Nonscience or Nonsense in Occupational Health $^{*}$}

K. C. WAN

Department of Occupational Health, Safety and Welfare, Western Australia (DOHSWA), and Occupational Health Society of Australia

Nonscience: Nonscience is a term coined by BJ Ford in his book "Nonscience or how to rule the world"1). It was coined for basic etymological reasons and is virtually self defining. "Non" is the prefix used to denote "not" and therefore whatever is not science is Nonscience.

Like the best terms of Nonscience itself, there are several ways to pronounce it. One way suggested by Ford is to adulterate the Science until it sounds like "see-ence" and the term acquires mystical almost oriental overtones. Another way is to rhyme it with conscience and it could well be the same as "nonsense"! The perpetrators of this new subject are so very far from those of the earlier men (women) of science they can hardly be called scientists. They have the same authority, the same status, the same bearing, and they have acquired the same responsibilities but they gain these attributes by entirely different means.

They utilise the mass media and call themselves "experts". Experts are no ordinary mortals. They are dedicated to data, facts and figures which can be made to substantiate any claim. Indeed, a truly devout Expert can use identical data on different occasions to substantiate entirely opposite points of view! The Expert is concerned primarily with what is news worthy or fashionistic according to Ford. Success is calculated on the basis of the space occupied and not accuracy. Should you wish to get on the bandwagon, read the book by Ford.

In the late $17 \mathrm{th}$ and 18 th centuries, there was a strong move to separate science out and distinguish it sharply from religion and philosophy and from the various forms of Pseudoscience such as consulting horoscopes. The definition of science in terms of empirical observation, experiment, induction of

Received March 13, 1995; Accepted Nov 9, 1995

Correspondence to: $K$. C. Wan, Department of Occupational Health, Safety and Welfare, Western Australia (DOHSWA), PO Box 294, West Perth WA 6005, Australia

* Paper based on address to the Occupational Health Society of Australia (OHSA) Inaugural Conference in the Burswood Convention Centre, Perth. Western Australia, Thursday, 12 November 1992 general laws, prediction and technologicals controls is associated with the 17 th century Englishman Francis Bacon.

It is the method of enquiry which distinguishes science form Nonscience and Pseudoscience. Its claims are based on empirical observation, experiment and inductive generalisation ${ }^{2)}$.

Thomas Kuhn, a theoretical physicist at Harvard in 1962 was of the view that normal science is a hum drum business largely concerned with what the scientific community as a whole chooses to accept as science. These paradigms or models dictate in effect what is to be considered science at any particular time and what is not.

For a new paradigm to succeed, it must solve the problem that have led the old one to a crisis and gain supporters who will develop it to the point where hard headed arguments can be produced and multiplied $^{3)}$.

It is relevant to identify the science in occupational health and differentiate it from nonscience or pseudoscience. It is also necessary to differentiate the role of science from the application of social values in decision making. Scientific principles and evidence have to be applied to determine hazard and risk whereas social vakues are applied to determine whether the risk posed by the hazard is acceptable.

The one fibre myth: Proponents of this theory say that any asbestos must be removed as 1 fibre could kill ${ }^{4)}$. This view is taken on the basis that there is no threshold at which asbestos will not cause cancer. The issue is further clouded by referring to the 1 fibre per $\mathrm{m} l$ of air Exposure Standard for Chrysotile (white asbestos). The Exposure Standard is not the same as inhaling in 1 fibre! $!^{5)}$.

The number of fibres breathed based on the Exposure Standard of 1 fibre per $\mathrm{m} l$ of air is estimated as follows :-

15 breaths $\times 500 \mathrm{~m} l$ tidal volume per minute $=$ $7,500 \mathrm{ml}$

Therefore, for a 7.5 hour working day $=7,500$ $\times 7.5 \times 60=3.38$ million $\mathrm{m} l$

Hence, number of fibres breathed based on the Exposure Standard of 1 fibre $/ \mathrm{m} l$

(a) per 7.5 hours working day $=3.38$ million fibres.

(b) per 230 working days in a year $=3.38 \times$ $230=776.3$ million fibres

(c) per 40 years working life $=31.5$ billion fibres $=14$ grams of fibres on the basis of fibres $3 u$ in diameter and $5 u$ in length.

e. g., Wittenoom workers 2,000 fibres per $\mathrm{m} l=$

6.75 billion fibres per 7.5 hours working day. Asbestos fibre counts on 126 lung specimens in 
Germany by Friederichs et $a l^{6)}$ showed Table 1.

Mesothelioma is a very rare tumour of the lining of the lung (pleura). In the general population it has an incidence of 1 in $1,000,000$. However, in blue asbestos workers the incidence is very high, e. g., Wittenoom employees. Once diagnosed, it is a verdict of death, usually within six months.

Seventy eight percent of mesothelioma patients with at least possible exposure to asbestos according to their history of work had concentrations of more than 1 million fibres per gram of dry lung tissue.

A $50 \mathrm{~g}$ dry weight lung of an adult mesothelioma patient without occupational exposure to asbestos could have 50 million fibres. The fibre concentrations in the lung tissue ranged from 100,000 fibres to 370 million fibres per gram dry lung ${ }^{7}$.

The concentration of asbestos in the air has been high in occupational groups during the periods of exposure between 1930 and 1965 before current standards were introduced. The 3 levels of exposures reported in Australia ${ }^{8,9)}$ are as follows :-

1. Historical occupational exposure

5 to 50 fibres $/ \mathrm{ml}$ (or even higher); mixed types

2. Current occupational exposure 0.25 fibres $/ \mathrm{ml}$, chrysotile

3. Levels in buildings 0.001 fibres $/ \mathrm{ml}$ (or less) ; mixed types

The Western Australian Occupational Safety and Health Act 1984 (OSHA) definition of hazard is "anything that may result in (1) injury to the person; or (2) harm to the health of the person. The definition of risk in relation to any injury or harm, means the probability of that injury or harm occurring $^{10)}$.

The Royal Society of London considered that an annual risk of 1 pet million was negligible and with this definition the risks due to exposure in buildings to very low concentrations of asbestos are in all cases estimated to be negligible. Available data do not support the concept that low level exposure to asbestos is a health hazard in buildings and schools ${ }^{(1)}$.

Oxford University's Sir Richard Doll and University of London Prof. Julian Peto estimated in 1985 that the risk of dying as a result of contracting dis-

Table 1. Exposure levels to asbestos and number of fibres per gram dry lung

\begin{tabular}{ll}
\hline Exposure to asbestos & Number of fibres per gram dry lung \\
\hline $\begin{array}{l}\text { No occupational } \\
\text { exposure }\end{array}$ & Less than 3 million \\
Transitional & $3-10$ million \\
Occupational & More than to million \\
\hline
\end{tabular}

ease from chrysotile asbestos (the most common from used) in buildings is one death in 100,000 lifetimes. Compare this with the other risks contained in Table 2.

Using this "worst case" approach, the Ontario Royal Commission estimated it would cost $\$ 80 \mathrm{mil}$ lion of asbestos removal activities to save one life ${ }^{12)}$.

Sick building syndrome (SBS): SBS should be called Sick People Syndrome (SPS) as it is people who are sick rather than the building ${ }^{13)}$. Proponents of SBS sometimes conclude that people cannot be sick according to mathematical or computer modelling and workplace measurements without examining the people! The solution lies not in measurements but to firstly determine whether people are sick followed by a workplace assessment to look for causes starting with the most common.

Lethargy, headache, blocked or runny nose, dry eyes and throat, and dry skin are collectively recognised as elements of the sick building syndrome. These symptoms are non specific and are common in the general population. Early work concentrated on trying to validate the symptoms, which are usually elicited by self or interviewer administered questionnaire. Most symptoms improve on days away from work. When environmental measurements are made they seldom fall outside recommended ranges, and the usual conclusion is that the occupants do not have the symptoms of which they are complaining.

A series of complaints about eye, skin and respiratory condition by employees at a primary school was investigated in $1989^{14)}$. There was no evidence from monitoring at the school, computer modelling and a report from University consultants that the problems were caused by air pollutants.

Medical examinations were then conducted in March 1989 on the employees at the school and compared with another primary school in a semi rural locality. All 24 employees in the school (100\%) had symptoms consistent with exposure to

Table 2. Cause of death : Lifetime risk per 100,000

\begin{tabular}{lr} 
Smoking & 21,900 \\
Motor vehicle accident & 1,600 \\
Cirrhosis of liver & 290 \\
Drowning & 140 \\
Home accidents & 88 \\
Cancer from diagnostic x-ray & 75 \\
Lightning & 3 \\
Asbestos in school buildings & 1 \\
\hline Figures from Summary of Symposium on Health Aspects of Exposure \\
to Asbestos in Buildings published by Harvard University Energy and \\
Environmental Policy Centre, August 1989.
\end{tabular}


airborne irritants of whom $19(79 \%)$ had physical signs on examination whereas none of the $12 \mathrm{em}$ ployees in the control school had symptoms or signs. The most frequent complaints were related to irritation of the throat (88\%), mouth/lips $(71 \%)$, eyes $(50 \%)$ and nose (46\%). These symptoms were consistent with the findings of inflammation of the throat $(54 \%)$, nose $(42 \%)$ and lesions in the mouth/lips (17\%) on physical examination.

Points of note in medical history included the following:-

1. Symptoms began when I commenced working in the school and I have not had such symptoms before.

2. Symptoms clear up or I feel better on the weekend or holidays and recur when I return to the school.

3. I have worked for many years in the school (long serving employee in the school) and have not had these problems until the past twelve months.

Repeat examinations were conducted in May/ June 1989 on 22 of the 25 employees at their new location of the school (response rate $88 \%$ ). The reduction in symptoms since March 1989 were highly statistically significant $(\mathrm{p}<0.00001)$.

Highly statistically significant improvements were observed in the lung function test results of employees when the May tests were compared with the March rests. Significance levels were $p<0.002$ for FEV $_{1}$ and $\mathrm{p}<0.0001$ for FVC and FVC observed/ FVC predicted percentage.

The urine fluoride levels of employees were statistically significantly higher than the control school employees $(p<0.01)$. Of the 24 employees, 18 (75\%) of the employees exceeded $1.5 \mathrm{mg}$ fluoride per gram creatinine. According to the World Health Organisation (WHO), in communities with drinking water fluoridated at $1 \mathrm{mg} / l$, the normal urinary fluoride levels range from 0.5 to $1.5 \mathrm{mg} / l^{15)}$. This normal value for fluoride per gram creatinine cited by Lauwerys is less than $0.5 \mathrm{mg}$ fluoride per gram creatinine ${ }^{16)}$.

These significantly higher urine fluorides could not be accounted for by ingested fluoride from the results of the questionnaire survey which showed that the intake of tea and canned fish which are the two common high sources of dietary fluoride in the school were about half that of control school employees. There was no difference in the use of fluoride dentifrice and fluoride in water of both schools was $1 \mathrm{ppm}$. The urine fluoride levels of employees had returned to normal when they were retested at their new location and were not significantly different statistically from the control school employees.
The results were consistent with the report of the Health Department of Western Australia on medical examinations conducted on school children in the school and schoolchildren of another control school in March 1989 which showed an excess in almost all symptoms and that the prevalence of almost all symptoms increased during the day.

Analysis of sickness absence of school children showed the number of absences of children living in a sector located east of the school had increased 62.5 times from 1.3 in 1986 to 81.3 in 1988 and the average number of absences per child had increased 17.7 times from 0.6 to 10.6 .

The Health Department of Western Australia epidemiological randomised control health survey in April 1989 of 31 of the 44 employees in a nearby public hospital (77\% response rate) and 23 of the 35 employees at another control hospital reported a higher prevalence of minor respiratory tract symptoms in the hospital located near the school. The report states that its findings are consistent with the presence of an airborne irritant.

Monitoring $\mathrm{SO}_{2}$, nitrogen oxides and fluoride in May 1989 for two weeks by Murdoch University identified significant concentrations of nitric oxide gas and fluoride concentrations showed an uneven distribution both spatially and in time. The peak concentrations at the sites with highest concentrations exceeded many short time environmental standards and guidelines. Hydrogen chloride measured at the school reached peaks above the odour threshold.

In June 1989, the Western Australian Environmental Protection Authority (EPA) reported that there is no doubt that some airborne irritant is present from time to time. The two most likely sources appeared to be:-

1. the brickworks;

2. the hospital's incinerator.

If airborne contaminants are responsible for symptoms whether acting alone or synergistically as components of a complex cocktail this may be due to several mechanisms, including toxicity, irritation, susceptibility or allergy. The sheer number and variety of suspected agents certainly argue against a unified pathogenic effect. The presumptive causative agent may be single or multiple but the illness is manifested by subjective symptoms triggered by the patient's encounter with a large number of different environmental chemicals, foods, food additives and drugs. Objective physical findings are absent. It is important to recognise these difficulties besides the limitations of air sampling and detection of causative agents in the investigation of air pollution complaints. It is essential to recognise that 
when people are complaining about their health, a problem exists which has to be investigated and resolved before arriving at a conclusion purely on a scientific basis. In conflict resolution and problem solving, it is necessary to take into account perceptions of the community, socio-economic and political factors.

In February 1992, many expensive and time consuming microbiological tests for disease causing organisms (pathogens) had been conducted in an office which had been flooded and had ducted refrigerated air-conditioning. The office was cleaned and disinfected but people were still sick. Medical examinations then showed that $80 \%$ of the $31 \mathrm{em}-$ ployees complained of unsatisfactory air-conditioning related to poor air circulation and $50 \%$ considered the temperature control within the building to be inadequate. About $30 \%$ complained of unacceptable odours within the building. Adopting a back to basics approach, the workplace was inspected and the work environment assessed. The assessment confirmed that ventilation and temperature in the office was inadequate. Further investigation showed that the air distribution system of the air-conditioning was defective ${ }^{17)}$. Symptoms of people in air-conditioned buildings are most commonly associated with temperature over $23^{\circ} \mathrm{C}$, lack of control of lighting, poor ventilation, standards of maintenance or space management ${ }^{18)}$.

What you see is what you get (WYSIWYG) is what the user of a computer would like to have. So would the user of occupational health information. It has been said that there are lies, more lies and statistics. For valid interpretation and effective decision making, the user requires reliable information.

In Western Australia, the cases of silicosis certified for workers' compensation by the Pneumoconiosis Medical Panel have declined from 33 cases in $1984 / 85$ to 4 cases in $1990 / 91^{19)}$. All these cases had commenced working in the mines before the Exposure Standard of $0.2 \mathrm{mg} / \mathrm{m}^{3}$ for crystalline silica was implemented in Western Australia in the 1960's.

The experience or actual occurrence in Western Australia since the 1960's has been that there have been no new cases of silicosis arising from the implementation of the $0.2 \mathrm{mg} / \mathrm{m}^{3}$ Exposure Standard for crystalline silica.

The case prevalence in the annual report does not reflect current exposure and therefore cannot be applied for prediction of case incidence. The risk assessment model ${ }^{20)}$ which predicts that if this exposure standard is adopted that there would be approximately 20 cases per year of silicosis averaged over the next 40 years is therefore not upheld by actual experience in Western Australia ${ }^{21)}$ and China ${ }^{22)}$.

\section{Conclusions}

1. Scientific principles and evidence have to be applied to determine HAZARD and RISK.

2. Social values are applied to determine whether risk posed by the hazard is ACCEPTABLE.

3. Validated information based on sound scientific principles and evidence are necessary for effective decision making.

Acknowledgement: The author wishes to thank the chief executive officer of Work Safe Western Australia for permission to present this paper.

\section{References}

1) Ford BJ. Nonscience or How to Rule the World. London: Wolfe Publishing Ltd, 1971.

2) Charlesworth M. Science, Nonscience and Pseudoscience, Deakin Univ Press, 1982.

3) Kuhn TS. The structure of scientific revolutions. In : International Encyclopaedia of Unified Science, Vol. 2, No. 2. University of Chicago Press, 1974.

4) Editorial. The asbestos removal fiasco. Science 1990 : $247 ; 1007$.

5) Wan KC. The health risks of asbestos and Synthetic Mineral Fibres (SMF), Western Australia Building Owners' and Managers' Association (BOMA) Forum 1991.

6) Friedrichs $\mathrm{KH}$, et al. Electron microscopy analysis of mineral fibres in human lung tissue. Amer JIM 1992: $22 ; 49-58$.

7) Tuomi T, et al. Occupational exposure to asbestos as evaluated from work histories and analysis of lung tissues from patients with mesothelioma, BJIM, 1991 : 48; 48-52.

8) National Occupational Health and Safety Commission. Asbestos: Code of Practice and Guidance Notes, August 1988, AGPS 88-89.

9) The Western Australian Advisory Committee on Hazardous Substances. Asbestos Cement Products, August 1990.

10) Occupational Safety and Health Act 1984, Western Australia.

11) Mosman BT, et al. Asbestos: Scientific developments and implications for public policy. Science, 1990: 247; 294-301.

12) Duffy M. Looking for Mr Fluffy. The Independent Monthly, 1991: 16 .

13) Lancet. Sick Building Syndrome 1991; 338: 14931494.

14) Wan KC. Urine fluorides and health status of employees of 2 primary schools in Western Australia, ANZSOM 1989 Scientific Meeting, Hobart, Tasmania. 
15) World Health Organisation, Geneva. Guidelines for drinking water quality, 1984.

16) Lauwerys R, Hoet P. Industrial Chemical Exposure. Lewis Publishers, 1993: 291.

17) Wan KC. Sick building syndrome: a case study. J Occupational Health Safety-AustNZ, 1994 : 10 ; 555559.

18) Friedman JM, et al. Controlling pollution of indoor office air. O Health \& Safety 1992 : Sept ; 16-22.

19) Workers' Compensation and Rehabilitation Commission (WA) Annual Report 1990/91 : 24.

20) Nurminen $\mathbf{M}$, et al. Prediction of silicosis and lung cancer in the Australian labor force exposed to silica. Scandinavian J Work Environment Health 1992; 18 : 393-399.

21) Wan KC, Lee E. Review of 110 silicosis cases certified for workers' compensation by the Western Australian Pneumoconiosis Medical Panel from 1983 to 1993. 14 th Asian Conference on Occupational Health, Beijing, 1994.

22) Liu ZY, et al. Exploration into prevention of pneumoconiosis in metal mines, Minesafe Conference Perth 1993. 